\title{
Perinephritis Hypertension in Monkeys
}

\section{An Increase of Plasma Renin Activity Associated with Increased Permeability of Retinal Vessels and Angionecrosis}

\author{
Toyoaki Okabayashi, M.D.,* Motoomi Nakamura, M.D., * \\ Akinobu Sumryoshi, M.D.,** Yoshisuke OKA, M.D.,*** \\ Koshiro Funiyama, M.D.,**** and \\ Hiroshi IKUI, M.D.***
}

\begin{abstract}
SUMmARY
The renal parenchyma of 5 crub-eating monkeys (Macaca irus) was wrapped by cellophane and plasma renin activity, blocd pressure and vascular permeability of ocular ground were measured in comparison with 5 unoperated control monkeys. The results demonstrated that increases of systolic arterial pressure, plasma renin activity, and permeability of the retinal vessels were found in 4 operated monkeys. There was no such abnormal finding in the unoperated control monkeys. Generally there was a rough parallelism among levels of plasma renin activity and systolic blood pressure, an increase of permeability of retinal vessels and fibrinoid angionecrosis and/or necrotizing angitis similar to polyarteritis nodosa.
\end{abstract}

\section{Additional Indexing Words :}

Crub-eating monkey Ocular ground Fluorescein microangiography

LYPERTENSION has been produced experimentally by various methods 1 in a wide variety of animals, and hypertension in dogs and rats has been most widely studied. The method of Page, ${ }^{1)}$ consisting of wrapping kidneys in silk or cellophane envelope, has advantages of simplicity of experimental technique and a slow but progressive elevation of arterial blood pressure. However, it is uncertain whether all types of the experimental hypertension have resulted from the same mechanism. In the type of Goldblatt hypertension, a series of reaction, such as changes of intrarenal pulsation or blood flow, renin, angiotensin, and aldosterone has been widely

From the Research Institute of Angiocardiology and Cardiovascular Clinic, ${ }^{*}$ Department of Pathology,** Ophthalmology, ${ }^{* * *}$ and Second Internal Medicine,**** Kyushu University Medical School, Fukuoka, Japan. Supported in part by the Research Foundation (Yamanouchi) on Metabolic Disorders.

Address for reprints: Motoomi Nakamura, Research Institute of Angiocardiology, Kyushu University Medical School, Fukuoka 812, Japan.

Received for publication March 31, 1975. 
confirmed in experimental and clinical cases. Although perinephritis hypertension has been produced in rats, rabbits, and dogs, studies in monkeys were very few, if any. In general, monkeys are more close to human. In the present study, the renal parenchyma of the monkeys was wrapped by cellophane and plasma renin activity, blood pressure being measured indirectly or directly, permeability of retinal vessels and histological changes of various organs were examined.

\section{Methods}

Ten monkeys (Macaca irus, crub-eating monkey) were obtained from the commercial source and divided into 2 groups, 5 animals served as unoperated controls (Exp. No. 1-5) and the remaining 5 monkeys (Exp. No. 6-10) were used to study the effects of cellophane perinephritis combined with unilateral nephrectomy as shown in Table I. Each monkey was housed in the individual metal cage at $25^{\circ} \mathrm{C}$ and fed a laboratory chow plus $250 \mathrm{mg}$ vitamin $\mathrm{C}$ twice a week. By the routine clinical examinations and observation for 1.5 months, monkeys were found healthy. The monkeys were anesthetized with sodium pentobarbital, and each flank was infiltrated with lignocaine. Cellophane was placed in $70 \%$ ethanol solution for 24 hours and then rinsed in sterile saline before use. The left kidney was freed from its bed, and a sheet of cellophane was placed over the kidney and secured by all embracing ligature around pedicle without compression. A caution was made to avoid an acute significant compression of the kidney parenchyma and an obstruction of the renal artery at the hilus of the kidney. The right kidney was removed 2 weeks later. Lincomycin $\mathrm{HCl}(300 \mathrm{mg})$ was given intramuscularly twice a day for 5 days after each operation. The systolic blood pressure was measured without anesthesia under training once in 3 weeks indirectly by use of sphygmomanometer cuff for child at the upper arm as used previously. ${ }^{2)}$ The experimental number, age, sex, and body weight of the unoperated control and the operated monkeys were demonstrated in Table I. Since No. 10 monkey died spontaneously

Table I. Age Sex, and Body Weight of the Experimental Group

\begin{tabular}{|c|c|c|c|c|c|}
\hline & No. & Age (years) & Sex & $\underset{(\mathrm{Kg})}{\text { Initial B.W. }}$ & $\underset{(\mathrm{Kg})}{\text { Final B.W. }}$ \\
\hline \multirow[t]{5}{*}{ Control } & 1 & 5 & $\sigma^{\pi}$ & 2.0 & 2.5 \\
\hline & 2 & 4 & 0 & 1.6 & 2.5 \\
\hline & 3 & 4 & 0 & 2.5 & 3.6 \\
\hline & 4 & 7 & q & 3.3 & 3.3 \\
\hline & 5 & 4 & 우 & 2.8 & 2.5 \\
\hline \multirow[t]{5}{*}{ Experimental } & 6 & 8 & 우 & 3.4 & 2.9 \\
\hline & 7 & 11 & $\delta$ & 4.4 & 3.5 \\
\hline & 8 & 5 & 우 & 3.5 & 4.0 \\
\hline & 9 & 6 & 우 & 3.0 & 2.5 \\
\hline & 10 & 13 & 0 & 6.5 & 4.5 \\
\hline
\end{tabular}


3 months after wrapping the kidney, most of the experimental group were sacrificed at approximately 3-4 months after wrapping the kidney, and only No. 9 was sacrificed at 6 months after.

During a course, under pentobarbital anaesthesia, venous blood was taken for plasma renin activity (PRA) and permeability of the retinal vessels was determined by fluorescein microangiography. Because primates-renins are capable of acting on human angiotensinogen, PRA of monkeys was measured by the method reported from our laboratory, in which human plasma protein fraction IV-4 was used as renin substrate. ${ }^{3 !}$ By this method, average values of normal young Japanese were $37 \mu \mathrm{g}$ angiotensin II formed per $\mathrm{ml}$ of plasma/18 hours and maximal amplification of PRA was obtained.

At the end of the experiment, the animals were anesthetized with pentobarbital sodium and catheter was inserted into the thoracic aorta and arterial blood pressure was recorded via a transducer with Nihonkoden-polygraph. The brain, heart, lungs, liver, spleen, pancreas, stomach, intestine, wrapped kidney, aorta and renal arteries were removed and fixed with $10 \%$ formalin for routine histological study. Some blocks of the wrapped kidney were also fixed in Bowie-Smith fixative. The following stains were used: hematoxylin and eosin, periodic acid Schiff (PAS) and alcian blue, elastica van Gieson, phosphotungstic acid hematoxylin (PTAH), and Bowie-Smith stain." Juxtaglomerular indices were calculated according to the method of Hartroft and Hartroft. ${ }^{5)}$

\section{Results}

All of the monkeys of the experimental group showed loss of appetite and loss of body weight after operation (Table I) and later some became less active after a significant rise of blood pressure and/or plasma renin activity. No. 7 developed jaundice at the end of the experimental period. None of the control group showed any abnormal finding.

1) Blood pressure

A systolic blood pressure was recorded serially during a course. All of both unoperated control and the operated monkeys showed a systolic blood pressure below $100 \mathrm{mmHg}$ during an observation period. The systolic blood pressure of the experimental group elevated very gradually after wrapping the left kidney and removing the right kidney as shown in Table II. Usually blood pressure started to rise at approximately 10 weeks after wrapping kidney except No. 8 monkey. No. 8 monkey did not develop any significant increase of arterial pressure throughout an experimental period. The maximum level of systolic blood pressure recorded indirectly without anesthesia during an experimental period appeared to correlate with that recorded directly under anesthesia at the time of sacrifice. The duration of maintenance of significant hypertension varied in a range of 5 to 17 weeks as shown in Table II. The systolic blood pressure of the un- 
Table II. Changes of Blood Pressure of the Operated Animals During an Experimental Period

\begin{tabular}{|c|c|c|c|c|c|c|c|}
\hline \multirow{3}{*}{ No. } & \multicolumn{6}{|c|}{ Blood Pressure (B.P.) } & \multirow{3}{*}{$\begin{array}{l}\text { Duration of } \\
\text { Significant } \\
\text { Elevation of } \\
\text { Blood Pres- } \\
\text { sure (weeks) }\end{array}$} \\
\hline & \multicolumn{5}{|c|}{ Indirect B.P. (after wrapping kidney (weeks)) } & \multirow{2}{*}{ Direct B.P.* } & \\
\hline & before & $2-3$ & $5-7$ & $10-12$ & $15-20$ & & \\
\hline 6 & 70 & 70 & 100 & 180 & 166 & $197 / 116$ & 9 \\
\hline 7 & 70 & 85 & 85 & 144 & 130 & $120 / 82$ & 5 \\
\hline 8 & 70 & 105 & 90 & 110 & 一 & $106 / 80$ & 0 \\
\hline 9 & 70 & 80 & 90 & 120 & 180 & $155 / 103$ & 17 \\
\hline 10 & 100 & 90 & 110 & 120 & 210 & + & 5 \\
\hline
\end{tabular}

+ No. 10 monkey died at 99 th day after wrapping the kidney, and direct measurement of the intra-arterial pressure was not recorded.

* Direct measurement of blood pressure was made at the end of experiment under anesthesia.

- not recorded.

Table III. Plasma Renin Activity, Vascular Permeability of Retinal Vessels and Juxtaglomerular Cell of the Kidney of the Operated Monkeys

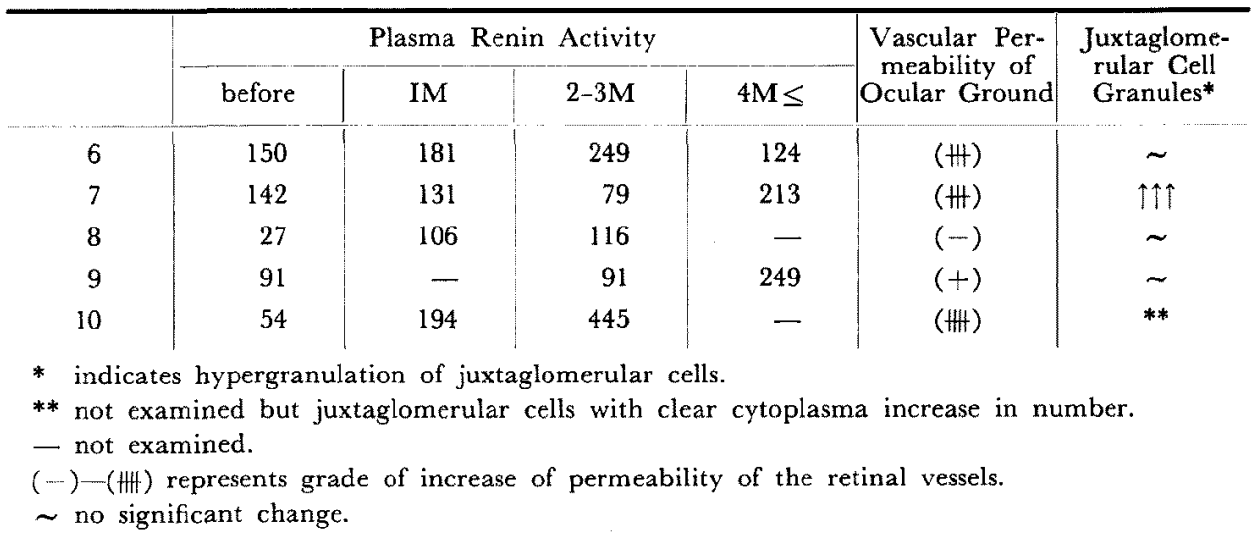

operated control animals remained below $100 \mathrm{mmHg}$ throughout an experimental period.

2) Plasma renin activity (PRA) and permeability of retinal vessels

PRA and vascular permeability of ocular ground of the operated monkeys were demonstrated in Table III and Fig. 1. PRA of 10 monkeys during an observation period was in a range of 49 to $165 \mathrm{ng}$ Angiotensin II formed per ml plasma per 18 hours in the control and 27 to 150 in the operated animals, These values of PRA in monkeys was slightly higher than normal average level of PRA of young Japanese being $37 \mathrm{ng} / \mathrm{ml}$ according to our method. ${ }^{3)}$ In Table III, PRA obtained during a course was demonstrated. PRA of the operated animals (No. 6-10) reached to maximum at 12, 13, 12,23 , and 11 weeks respectively after wrapping the kidney, and PRA of 

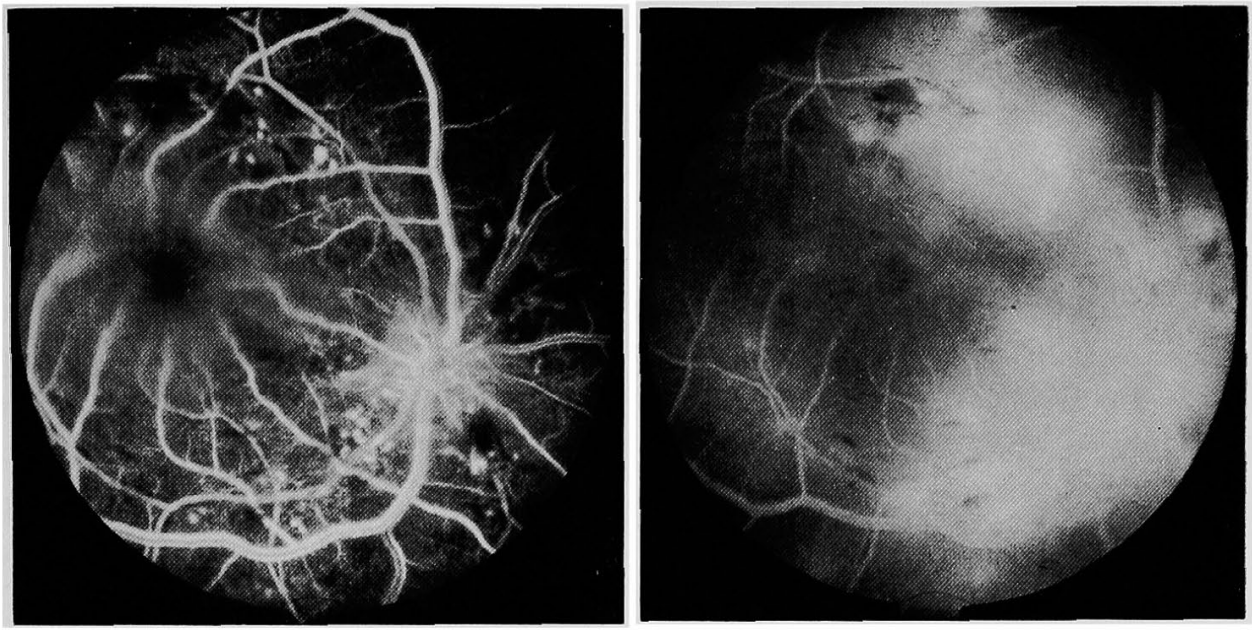

Fig. 1. Fluorescein angiograms of the fundus of No. 7 monkey.

(a) $38 \mathrm{sec}$ after the dye injection showing dilatation and irregularity of the capillary network and many microaneurysms.

(b) $897 \mathrm{sec}$ after the dye injection clearly demonstrating an increased permeability of the retinal capillary bed and microaneurysms. However the large vessels still show normal permeability.

No. 6 and 9 decreased thereafter to the value of 124 and 81 respectively despite a continuous hypertension. Vascular permeability of No. 9 monkey was examined at 20th, 23rd, and 25th week after wrapping kidney and increased slightly only at 25 th week examination.

An increase of PRA and vascular permeability in No. 10 monkey was the greatest in the operated monkeys and this animal died soon after he showed maximum PRA, $445 \mathrm{ng} / \mathrm{ml}$. There was a rough parallelism between PRA and grade of an increase of vascular permeability or of systolic blood pressure. However, the grade of granulation of the juxtaglomerular cell of the wrapped kidney did not show a significant correlation with PRA or vascular permeability or blood pressure elevation as shown in Table III.

3) Histopathological observations

None of the unoperated control monkeys showed any significant histopathological changes.

Kidneys of the operated monkeys showed fairly significant pericapsular fibrosis (perinephric hull), extending around the entire kidney. In No. 10 monkey, fibrotic change was severe and resulted in the distortion of the renal artery. However in No. 6 and 7 monkeys, involvement of pedicle produced no narrowing of the renal artery. Shrinkage of the cortical convoluted tubules was not significantly observed. Therefore, we considered that ischemic atrophy of the convoluted tubules was not produced in this experi- 


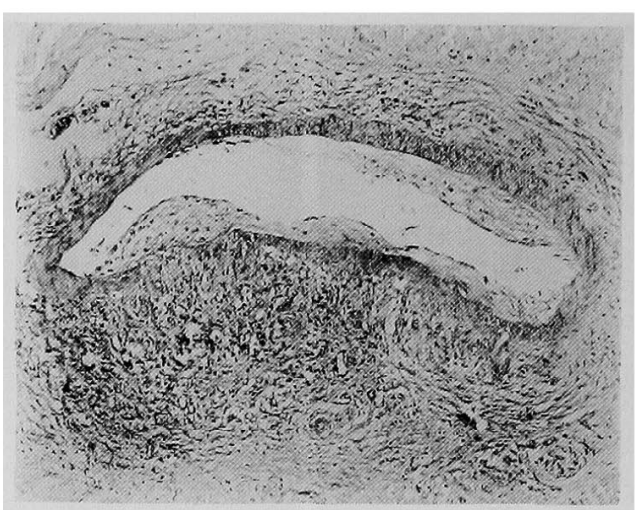

Fig. 2. Left descending coronary artery from No. 6 monkey.

Chronic lesion of polyarteritis nodosa is seen, associated with intimal fibrous thickening. E. E. $\times 70$

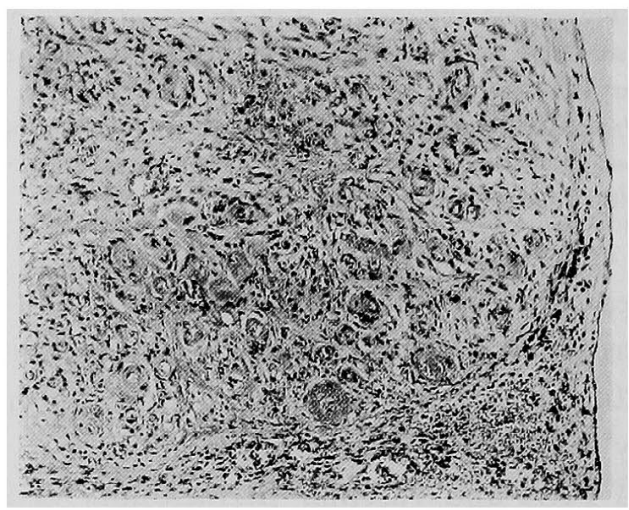

Fig. 3. Right atrial appendage of No. 10 monkey.

Fibrinoid necrosis or hyalinization of arterioles is seen. Hemorrhage, hemosiderin deposition, fibrosis and chronic inflammatory infiltrate are also present. H. E. $\times 88$

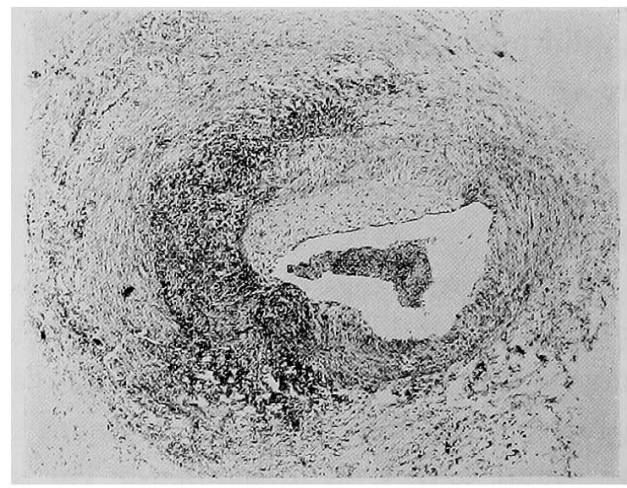

Fig. 4. Left coronary arteries from No. 10 monkey.

The arterial wall is involved by granulation tissue with intimal and adventitial fibrosis. Necrotic focus of the media still remains. H. E. $\times 40$. 
ment and also that a significant stenosis of the renal artery to produce Goldblatt type hypertension was not produced except for No. 10 monkey. The extrarenal arteries at the hilus of the kidney, arteries and arterioles of other splanchnic organs, coronary arteries such as the left anterior descending branch and arterioles in the right atrial appendage showed a significant lesion, fibrinoid necrosis suggesting a malignant phase of hypertension and/or necrotizing angitis of medium sized artery histologically compatible with polyarteritis nodosa (Figs. 2-4). The appearance of the arterial lesions was quite polymorphic even in the same instance. In some lesions the polyarteritic change involving the all layers of the medium-sized arteries was predominant and in others fibrinoid arteriolar necrosis was evident. Fibrinoid arteriolar necrosis was found in 3 out of 5 experimental monkeys as shown in Table IV. This finding reflecting an increase of the arteriolar permeability corresponded very nicely with the clinical findings of the increased permeability of the retinal vessels (see Table III and Fig. 1). These fibrinoid changes were indistinguishable from a finding of malignant hypertension. However, in the present study, systolic blood pressure of the No. 6, 7, and 10

Table IV. Histological Changes of the Operated Monkeys

\begin{tabular}{|c|c|c|c|c|c|c|}
\hline $\begin{array}{l}\text { No. of } \\
\text { monkey }\end{array}$ & $\begin{array}{l}\text { Fibrinoid necrosis or } \\
\text { periarteritis nodosa } \\
\text { of the artery (A) }\end{array}$ & $\begin{array}{l}\text { Periarterial } \\
\text { plasma leakage } \\
\text { or hemorrhage }\end{array}$ & $\begin{array}{l}\text { Significant } \\
\text { stenosis of } \\
\text { renal } \\
\text { artery }\end{array}$ & $\begin{array}{l}\text { Pericap- } \\
\text { sular } \\
\text { fibrosis }\end{array}$ & $\begin{array}{l}\text { Basilar } \\
\text { artery }\end{array}$ & Aorta \\
\hline 6 & $\begin{array}{l}\text { coronary } A \text { (LAD) and } \\
\text { right atrial appendage }\end{array}$ & $\begin{array}{l}\text { cerebral basal } \\
\text { nuclet, atrial } \\
\text { appendage } \\
\text { (hemosiderosis) }\end{array}$ & - & + & - & $\begin{array}{l}\text { localized } \\
\text { fibrous } \\
\text { thicken- } \\
\text { ing }\end{array}$ \\
\hline 7 & $\begin{array}{l}\text { Coronary } A \text { (LAD), right } \\
\text { atrial appendage, splan- } \\
\text { chnic arteries, pancreas, } \\
\text { stomach, duodenum, } \\
\text { gallbladder, extrahepatic } \\
\text { bile duct*, splcen, brain }\end{array}$ & $\begin{array}{l}\text { cerebral basal } \\
\text { nuclei }\end{array}$ & $\begin{array}{l}\text { fibrous } \\
\text { thicken- } \\
\text { ing of the } \\
\text { intima }\end{array}$ & + & - & $\begin{array}{l}\text { fibrous } \\
\text { plaque }\end{array}$ \\
\hline 8 & - & - & - & + & - & $\begin{array}{l}\text { calcifica- } \\
\text { tion, small } \\
\text { fibrous } \\
\text { plaque }\end{array}$ \\
\hline 9 & - & - & $\cdots$ & + & - & $\begin{array}{l}\text { fibrous } \\
\text { thicken- } \\
\text { ing and } \\
\text { fibrous } \\
\text { plaque }\end{array}$ \\
\hline 10 & $\begin{array}{l}\text { Coronary } A \text { (LAD) and } \\
\text { right atrial appendage, } \\
\text { external arterioles at } \\
\text { the hilus of the wrapped } \\
\text { kidney }\end{array}$ & $\begin{array}{l}\text { cerebral and } \\
\text { cerebellar corti- } \\
\text { ces and basal } \\
\text { nuclei }\end{array}$ & $\begin{array}{l}\quad+ \\
\text { (periarte- } \\
\text { rial fibro- } \\
\text { sis) }\end{array}$ & H & $\begin{array}{l}\text { localized } \\
\text { fibrous } \\
\text { thicken- } \\
\text { ing }\end{array}$ & - \\
\hline
\end{tabular}

* with obstructive jaundice. 


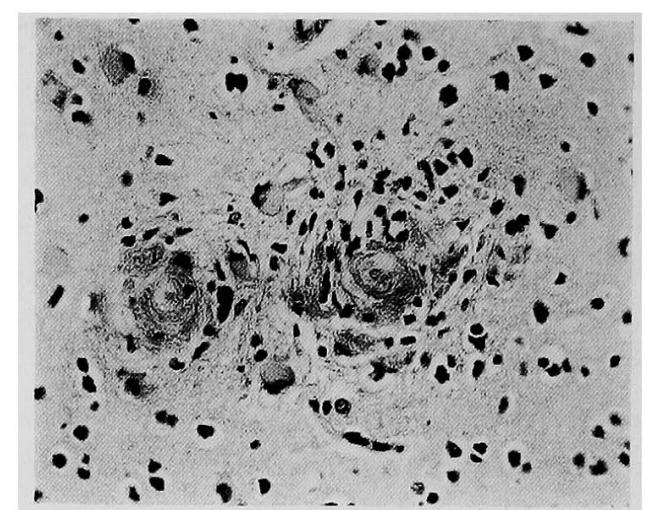

Fig. 5. Cerebral cortex of the temporal lobe of No. 7 monkey.

Necrotizing arteriolitis is seen associated with the perivascular round cell infiltrate and gemistrocytic proliferation. H. E. $\times 290$

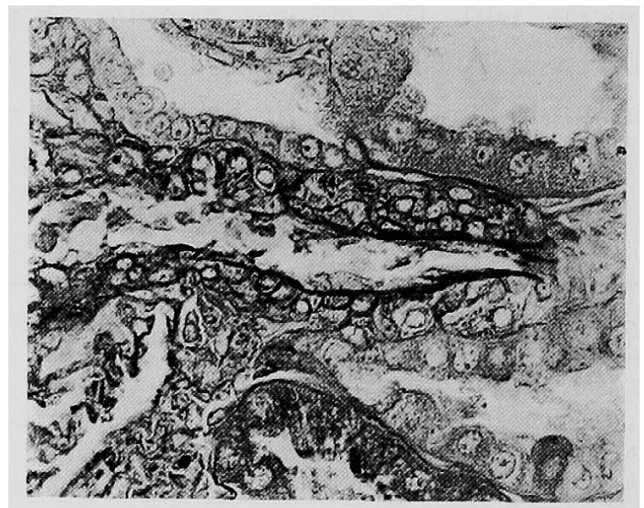

Fig. 6. Vascular pole of the glomerulus showing longitudinal plane of afferent arteriole from No. 7 monkey.

Hyperplastic and hypergranulated juxtaglomerular cells are seen extended to the wall of arteriole away from the glomerulus. Bowie-Smith

monkeys who showed a significant fibrinoid necrosis, was only 180, 144, and $210 \mathrm{mmHg}$ respectively as a maximum record. A periarteriolar plasma leakage with or without the arteriolar lesion and hemorrhage were found on the cerebral cortex and basal nuclei and cerebellar nucleus (Fig. 5). In general, vascular changes in the brain were recent and mild, but in the coronary arteries rather old and advanced. However, there was no focal myocardial necrosis or hemorrhages beneath the endocardium. The juxtaglomerular cells were histologically altered in 2 monkeys, No. 7 and 10 of the experimental group as shown in Table III. An increase in number of juxtaglomerular cells of epithelioid cell type and some hypergranulation were demonstrated. However neither juxtaglomerular hyperplasia nor hypertrophy was consistently found in the monkeys showing a significant elevation 
of blood pressure. One monkey (No. 7) out of 4 sacrificed animals of the 5 operated monkeys demonstrating an increase of PRA, showed a hypergranulation of juxtaglomerular cells and an increase of epithelioid cells with clear cytoplasm (Fig. 6 and Table III). No. 10 showed also an increase of epithelioid cells, but its granulation was not examined because of spontaneous death. Interstitial cortical fibrosis and a contraction of scar tissue were not observed.

Some glomeruli showed a diffuse ischemic changes, such as thickening of the basement membrane of the tufts and hyalinization. In general, the large arteries showed no remarkable changes. In the basilar artery of No. 10 monkey, a localized fibrous thickening was found. No. 6, 7, 8, and 9 monkey showed a mild and small localized intimal fibrous thickening of the aorta.

\section{Discussion}

There are very few studies, if any, on the experimental perinephritis with or without unilateral nephrectomy in monkeys and on the permeability of retinal vessels in perinephritis hypertension.

In the present study, all of the 5 operated monkeys produced a significant perinephritis, and 4 out of 5 monkeys produced a gradual elevation of arterial pressure, PRA above 200 and permeability of retinal vessels. None of the unoperated control monkeys showed such abnormal findings. Jaundice developed in No. 7 monkey appeared to result from periarteritic changes in the wall of extrahepatic bile ducts and gallbladder.

The role of renin release in perinephritis hypertension still remains unknown. Protection of intrarenal arterioles from hypertensive disease and occurrence of pressure drop within the renal vascular system have been shown by others in perinephritic animals. ${ }^{6},{ }^{7)}$ In this respect, perinephritis may be viewed as being similar to the Goldblatt procedure.

The results obtained in the present study, in which 4 out of 5 perinephritic monkeys showed a high level of PRA, are consonant with those in rabbits by Lewis and Lee.8) However, Campbell et al reported a decrease of renin secretion during the evolution of perinephritis hypertension in rabbits. ${ }^{9}$ Acute renal parenchymal compression can cause immediate renin release ${ }^{10}$ ) and simple laparotomy has been shown to cause renin release and elevation of plasma renin activity. ${ }^{11)}$ However, in the present study, PRA appeared to increase in later stage after operation and maximum activity was obtained from 11 to 23 weeks after operation. Therefore an increase of plasma renin activity in the present experiment cannot be ascribed to these mechanisms. 
An elevation of PRA above 200 appeared to bear some relationship to the arterial pressure. Returning of increased PRA to a preoperative level in the later stage of No. 6 and 9 monkeys might be due to a rise of renal perfusion pressure to normal after the significant hypertension, because PRA decreased after rise of blood pressure and a significant degenerative atrophy of the renal parenchyma was not found. However, in No. 10 monkey, PRA increased dramatically and was maintained at a high level until spontaneous death. In this animal, some distortion of the hilar renal artery due to perinephritic fibrosis was found at necropsy, and PRA and blood pressure rose approximately 12 weeks after wrapping kidney. Therefore, we considered that stenosis of the renal artery due to distortion in No. 10 monkey resulted not from a surgical error, but from an extension of severe perinephric hull to pedicle causing a significant obstruction of the renal artery.

Fibrinoid angionecrosis or periarteritic lesions and increased permeability of retinal vessels of No. 6, 7, and 10 monkeys are comparable to those occurring in human malignant hypertension. However, in No. 9 monkey, increases of PRA and permeability of retinal vessels were obtained at much later stage, such as 5 months or more after wrapping kidney. This might explain why no histological finding of angionecrosis was observed in No. 9 monkey. In No. 6 and 7 monkeys, no constriction of the renal arteries was confirmed by necropsy and histological examinations. Therefore, it appeared that perinephritis alone could produce an increase of PRA and permeability of retinal vessels in the monkey. There was relationship between a level of PRA and increased permeability of the retinal vessels. And also, a severity of increased permeability of the retinal vessel corresponded to that of periarteriolar plasma leakage in the brain as shown in Table IV. However, no relationship between a degree of juxtaglomerular granulation and PRA was found. This finding is consonant with other studies. ${ }^{12}$ )

Details of the histological and electron microscopic changes of the retinal vessels and fundoscopy will be published in a separate paper. Surprisingly informations on the permeability of the retinal vessels in the hypertensive monkeys are scanty, especially by use of fluorescein microangiography.

Ashton et al reported that only one case of hypertensive monkey produced by Goldblatt type operation associated with enclosing contralateral kidney by rubber balloon, developed retinal lesions comparable to those seen in human malignant hypertension. $\left.{ }^{13}\right)$

It is uncertain yet whether angionecrosis is the direct result of mechanical distension caused by raised intravascular tension, or result of ischemia due to prolonged spasm or other mechanisms.

Although we must consider some inpreciseness of blood pressure reading 
in the animals, it was consistently found that the rate at which blood pressure rose was rather gradual and the level of hypertension was not so severe. And yet an increase of the retinal vascular permeability was found in 4 out of 5 operated monkeys. This rate of incidence of malignant type lesions was higher than that of the perinephritic hypertension in dogs studied by Page, being $10 \% \cdot{ }^{14)}$

It has been suggested that while raised blood pressure is an important factor for angionecrosis, the humoral factors, such as renin, may produce angionecrosis. ${ }^{15), 16)}$

Recently, we reported that lysosomal contents of rat kidney cortex contained substances to induce an increase of vascular permeability and angionecrosis which would appear to be different from renin. ${ }^{17)}$ Whether an increase of PRA bore some responsibility for the raised pressure and what kind of substances in the kidney are responsible for angionecrosis in the perinephritis hypcrtension of monkeys are not known yet.

\section{REFERENCES}

1. Page IH: A method for producing persistent hypertension by cellophane. Science 89:273, 1939

2. Nakamura M, Murakami $\mathrm{H}$, Shigemi $\mathrm{U}$ : Effects of excess $\mathrm{NaCl}$ intake on blood pressure and cholesterol induced atherosclerosis in monkey. Stroke 6: 9, 1975

3. Arakawa K, Minohara A, Yamada J, Uemura N, Nakamura M: Micro-determination of human plasma renin activity with the addition of homologous substrate. Clin Chim Acta 22: 309,1968

4. Luna LG: Manual of Histologic Staining Methods of Armed Forces Institute of Pathology. 3rd Ed, McGraw Hill, New York, 1968

5. Hartroft PM, Hartroft WS: Studies on renal juxtaglomerular cells. I. Variations produced by sodium chloride and desoxycorticosterone acetate. J Exp Med 97: 415, 1953

6. Graef I, Page IH: The pathological anatomy of cellophane perinephritis. Am J Path 16: 211,1940

7. Campbell WGJ, Santos-Buch CA: Widely distributed necrotizing arteritis induced in rabbits by experimental renal alterations. Am J Pathol 35: 439, 1959

8. Lewis PJ, Lee MR: Plasma renin activity in the rabbit with renal hypertension. Brit $J$ Exp Path 52: 478, 1971

9. Campbell DJ, Skinner SL, Day AJ: Cellophane perinephritis hypertension and its reversal in rabbits. Effect of plasma renin, renin substrate and renal mass. Circulat Res 33: 105, 1973

10. Skinner SL, McCubbin JW, Page IH: Control of renin secretion. Circulat Res 15: 64, 1964

11. McKenzie JK, Ryan JW, Lee MR: A rapid simple method for the assay of renin in rabbit plasma. Biochem J 108: 679, 1968

12. Varkarakis MJ, Mandalenakis N, Mirand EA, Murphy GP: The juxtaglomerular apparatus in renal allograft resection; histological and ultrastructural study. Angiology 23: 401, 1972

13. Ashton N, Cunha-Vaz JG: Effect of histamine on the permeability of the ocular vessels. Arch Ophthal (Chicago) 73: 211, 1965

14. Page IH, Salmoiraghi GC, McCubbin JW: Observations on the method of producing perinephric experimental hypertension. J Lab Clin Med 46: 914, 1955 
15. Masson GMC, Corcoran AC, Page IH: Renal and vascular lesions clicited by "renin" in rats with desoxycorticosterone hypertension. Arch Path 53: 217, 1952

16. Masson GMC, Mikasa A, Yasuda $\mathrm{H}$ : Experimental vascular disease elicited by aldosterone and renin. Endocrinology 71: 505, 1962

17. Nakamura M, Murayama I, Sumiyoshi A, Kai M, Kanaide H, Naito S, Kato K: Renal subcellular fractions producing angionecrosis and increased vascular permeability. Brit J Exp Path 56: 62,1975 